\title{
ТОПОНИМИЧЕСКОЕ ПРОСТРАНСТВО ЭРЗЯ-МОРДОВСКОГО СЕЛА МОРДОВО-АДЕЛЯКОВО САМАРСКОЙ ОБЛАСТИ
}

\section{TOPONYMIC AREA OF THE ERZYA- MORDOVIAN VILLAGE "MORDOVO- ADELYAKOVO", SAMARA REGION}

N. Belenov

Summary: The article introduces and analyzes the components of the toponymic area of the Erzya-Mordovian village "Mordovo-Adelyakovo" in the Isakly district of the Samara region. The main attention is paid to the two most important components of the toponymic area: geographical lexicon and toponymic nomenclature. The elements of these components are analyzed using relevant data from other Mordovian toponymic areas of the Samara Volga region, neighboring regions, and the Republic of Mordovia. The article is based on the author's field materials obtained during the 2017 - 2019 seasons.

Keywords: toponymy, Mordovian languages, geographical lexicon, toponymic area, Mordovo-Adelyakovo.
$\mathrm{B}$ первые мордовская деревня Аделяково упоминается в материалах третьей ревизии 1762 года [3]. Согласно местным историческим преданиям, а также ряду косвенных указаний, основание села можно отнести к 1754 году. Какие именно населённые пункты явились исходными для эрзянских переселенцев в настоящее время неизвестно, устных преданий об этом в их среде также не сохранилось. При этом доподлинно известно, что эрзяне переселялись совместно с чувашами - подобная ситуация нередка для Самарского Поволжья. Совместные переселения и смешанные, чувашско-мордовские, сёла исторически фиксируются на Самарской Луке, в Клявлинском, Исаклинском, Шигонском, Челно-Вершинском районах. Также надо отметить, что, с течением времени, мордва и чуваши, как правило, расселялись по отдельным населённым пунктам. В рассматриваемом случае это произошло сразу после покупки земли у башкирских тарханов: чуваши основали село, известное в настоящее время как Кармало-Аделяково. В основе названий указанных сёл, по-видимому, лежит чувашский антропоним Этелек, при этом в исторических преданиях аделяковских чувашей и эрзян фигурируют совсем другие имена - Осип Мозгуев, Герасим Гаврилов и Никифор Куликов [4].

При анализе топонимической номенклатуры, бытующей в том или ином говоре, существенное значение имеет знание особенностей данного говора, в которых нередко находится ключ к верному этимологическому

\author{
Беленов Николай Валерьевич \\ К.n.н., дочент, Самарский государственный \\ социально-педагогический университет \\ belenov82@gmail.com
}

Аннотация: В статье вводятся в научный оборот и анализируются компоненты топонимического пространства эрзя-мордовского села МордовоАделяково Исаклинского района Самарской области. Основное внимание уделяется двум важнейшим составляющим топонимического пространства: географической лексике и топонимической номенклатуре. Элементы указанных составляющих анализируются с помощью привлечения соответствующих данных других мордовских топонимических пространств Самарского Поволжья, соседних регионов, Республики Мордовия. Статья опирается на полевые материалы автора, полученные в ходе сезонов 2017 - 2019 гг.

Ключевые слова: топонимика, мордовские языки, географическая лексика, топонимическое пространство, Мордово-Аделяково.

решению. В связи с этим, отметим некоторые отличительные особенности мордовоаделяковского говора.

Прежде всего, в мордовоаделяковском говоре эрзямордовского языка выделяется замена литературно-письменного эрзя-мордовского [ц] на [с], сравните: улься вместо ульця - 'улица', икельс вместо икельце - 'передний' и т.д.

Также надо отметить нерегулярную редукцию последних гласных в данном говоре, которая может объясняться особенностями акцентологии - ударение здесь чаще всего приходится на последний слог.

Отметим также, что аффриката [ч] в данном говоре жёсткая - как и в большинстве эрзя-мордовских говоров региона, исключения по данному пункту составляют лишь шиланский, большекаменский и степношенталинский эрзя-мордовские говоры (в последнем прослеживается недавнее смягчение данной аффрикаты).

Географическая лексика рассматриваемого говора, в целом, соответствует таковой в литературно-письменном эрзя-мордовском языке. одним из существенных отличий стоит признать факт отсутствия в мордовоаделяковском говоре, так же как и в эрзя-мордовских говорах расположенных рядом сёл - Мордово-Ишуткино и Захаркино, в настоящее время термина эрьке для обозначения озёр. При этом надо отметить, что в топонимической номенклатуре окрестностей Мордово-Аделяково и 
Захаркино данный термин встречается - однако, его семантика на современном этапе не подлежит однозначной трактовке (ПМА, Самарская область, Сергиевский район, Захаркино, 2019). Данная ситуация находит параллели в географической лексике мордвы Самарского Поволжья [1].

Рассмотрим последовательно элементы топонимической номенклатуры села Мордово-Аделяково и его окрестностей.

Aло ne Название низинного района села МордовоАделяково. Топоним происходит от эрзя-мордовских лексем: ало - 'низменный' + ne - 'конец' = 'нижний конец'. Данный элемент топонимического пространства отмечается практически во всех эрзянских сёлах Самарского Поволжья.

Базьма латко Название в Мордово-Аделяково реки Базьмы у Старого Вечканово. Информаторы объясняли нам данное название так: «Вот у Вечканово есть овраг Базьма латко. И вот откуда это название пошло? Ну ладно, латко - знаем (что такое - Н.Б.), а базьма - кто знает?» (ПМА, Самарская область, Исаклинский район, Мордово-Аделяково, 2019). Потамоним Базьма, по-видимому, был деэтимологизирован у вечкановской мордвы уже на рубеже XIX - XX веков, поскольку X. Паасонен, в своих подробных материалах по Старому Вечканово ограничивается в данном случае лишь указанием: «Базьма - река у Старого Вечканово» [6]. Тот факт, что в Мордово-Аделяково данный объект называется Базьма латко, а не Базьма лей, указывает на то, что первоначально так обозначались верховья реки, где она мелкая и иногда пересыхает.

Березовка Название части улицы в селе МордовоАделяково. Со слов информаторов: «Там берёзки растут, поэтому Березовка» (ПМА, Самарская область, Исаклинский район, Мордово-Аделяково, 2019). Идентичные названия имеют значительное распространение в топонимических пространствах эрзя-мордовских сёл Самарского Заволжья.

Bepe ne Название возвышенной части села МордовоАделяково, где ныне располагаются здания сельского клуба и школы. Топоним происходит от эрзя-мордовских лексем: вере - 'вверху; сверху' + пе - 'конец' = 'верхний конец'. Данный элемент топонимического пространства типичен для эрзянских сёл региона, составляя, в большинстве случаев, дуальную систему с элементом Ало пе.

Вишке моховой Название одного из ручьёв в окрестностях Мордово-Аделяково и Мордово-Ишуткино. Топоним является гибридным: эрзя-мордовское вишке - 'малый, маленький' + русское моховой = 'малый моховой' (ручей). Интересно, что общемордовская лексема для обозначения мха - нупонь - практически неизвестна в мордовских говорах Самарского Поволжья. В говорах рассматриваемых сёл она заменяется заимствованием из русского языка. Название ручья объясняется тем, что он протекает по низменным, зачастую покрытым мхом, местам.

Вылетаевка Название одной из улиц в селе Мордово-Аделяково. Со слов информаторов: «Улица расположена на выезде из села, в сторону Ишуткино, поэтому так и называется» (ПМА, Самарская область, Исаклинский район, Мордово-Аделяково, 2019).

Деревяшкань лисьма Источник, из которого осуществляется забор воды для водоснабжения села Мордово-Аделяково. Топоним этимологизируется следующим образом: деревяшка - заимствование из русского языка + нь - аффикс принадлежности в мордовских языках + лисьма - 'источник; родник' = 'деревяшкин родник'. Источник назван так потому, что был облагорожен деревянной колодой (ПМА, Самарская область, Исаклинский район, Мордово-Аделяково, 2019).

Дигонь лисьма Родник в урочище Асказанка. Со слов информаторов в Мордово-Аделяково: «Дигонь - это по имени человека, родник так назван, около Асказанки. Там деревня раньше была, а теперь одно кладбище осталось» (ПМА, Самарская область, Исаклинский район, Мордово-Аделяково, 2019). Представляется, однако, что в основе названия родника лежит эрзя-мордовское дига - 'гусь'. В мордовоаделяковском говоре эрзя-мордовского языка вместо орнитонима дига бытует орнитоним гала (данная форма встречается в большинстве эрзя-мордовских говоров Самарского Поволжья), поэтому, видимо, информаторы из этого села и возводят основу названия родника к антропониму. Впрочем, что это за имя - Дигонь - им неизвестно. Наряду с этим, в захаркинском говоре эрзя-мордовского языка гусь обозначается лексемой дига, что даёт основания для нашего предположения. Таким образом, этимология топонима следующая: дига - 'гусь' + нь - аффикс принадлежности в мордовских языках + лисьма - 'источник, родник' = 'гусиный родник. Топоним имеет семантические параллели в топонимических пространствах ряда эрзя-мордовских сёл Самарского Заволжья - например, в Клявлинском районе (ПМА, Самарская область, Клявлинский район, Старые Сосны, 2019).

Ииуткина лей Река, протекающая через село Мордово-Ишуткино. Название является двусоставным: Ишутка - антропоним + на - русский аффикс принадлежности + лей - 'река, ручей' = 'Ишуткина речка'. Интересно отметить, что в сходной ситуации, в ареально близком к Мордово-Ишуткино селе Захаркино, подобная форма гидронима не сформировалась и река называется просто Захарка (ПМА, Самарская область, Серги- 
евский район, Захаркино, 2019).

Карамалка Урочище в окрестностях сёл МордовоАделяково и Мордово-Ишуткино. В отличие от большинства подобного рода топонимов в Самарской области, произносится в мордовоаделяковском и мордовоишуткинском говорах именно так - Карамалка, а не Кармалка. Название урочища, по всей видимости, восходит к гидрониму, а тот, в свою очередь, к чувашскому флорониму хурама со значением 'вяз'. В топонимии Самарского Поволжья чувашские названия, восходящие к данной лексеме, как правило, в русской передаче имеют формы кармалка или кармала. В случае названий рек потамоним в чувашском языке формируется следующим образом: хурама - 'вяз' + ла - аффикс прилагательного в чувашском языке = хурамала - кармала. В случае названий сёл ойконим формируется следующим образом: хурама -'вяз' + ял - 'село' + е - аффикс принадлежности в чувашском языке = хурама ялӗ - кармала. В рассматриваемом случае в эрзя-мордовских говорах выпадения гласного из чувашского названия не произошло, вследствие чего имеем форму карамалка вместо кармалка.

Икельс улься Название одной из улиц в селе Мордово-Аделяково. Со слов информаторов: «Эта улица у нас в селе самая близкая к дороге была, поэтому назвали её Икельс - Передняя» (ПМА, Самарская область, Исаклинский район, Мордово-Аделяково, 2019). Топоним двусоставный: икельс - 'передний' (литературно-письменная эрзя-мордовская форма - икельце) + улься - фонетически адаптированный в эрзя-мордовской этноязыковой среде русский термин улица = 'передняя улица'.

Кузьмань лисьма Название родника, расположенного в лесу в окрестностях села Мордово-Ишуткино. Топоним является двусоставным, переводится с эрзя-мордовского языка на русский следующим образом: Кузьма - антропоним + нь - мордовский аффикс принадлежности + лисьма -'родник' = родник Кузьмы.

Лугань пень лисьма Родник в селе Мордово-Ишуткино, со слов информаторов его перевод на русский язык означает 'Красивый родник' (ПМА, Самарская область, Исаклинский район, Мордово-Ишуткино, 2019). Родник с таким названием действительно имеется в окрестностях села, данное же название буквально переводится на русский язык иначе: луга - фонетически адаптированное в эрзя-мордовской этноязыковой среде заимствование из русского языка луговой + ne - 'конец; часть села' + ньмордовский аффикс принадлежности + лисьма - 'родник' = 'родник луговой улицы'.

Мазы лисьма Родник в окрестностях сёл Мордово-Аделяково и Мордово-Ишуткино. Топоним является двусоставным, его перевод с эрзя-мордовского языка на русский имеет вид: мазы - 'красивый' + лисьма - 'род- ник' = 'красивый родник'. Название дано по окружающей источник местности, которая считается здесь наиболее живописной.

Мазынь лугась Луга в окрестностях сёл МордовоАделяково и Мордово-Ишуткино. Топоним переводится с эрзя-мордовского языка на русский следующим образом: мазы - 'красивый' + нь - аффикс принадлежности в мордовских языках + луга - фонетически адаптированное в эрзя-мордовской среде заимствование из русского языка + сь - аффикс определённости в мордовских языках = 'луг красивого (родника)', поскольку в окрестностях данного луга находится родник Мазы лисьма. Вообще, лексема мазы - 'красивый' часто фигурирует в составе географических названий данных топонимических пространств.

Мерганьлей Река в окрестностях сёл Мордово-Аделяково и Мордово-Ишуткино. Потамоним неясной этимологии. Со слов информаторов: «Мерганьлей - есть такое, это речка. Почему так называется - никто не знает» (ПМА, Самарская область, Исаклинский район, Мордово-Аделяково, 2019). Потамоним можно представить в следующем виде: мерга - основа без ясной этимологии + нь - мордовский аффикс принадлежности + лей - 'река'. Таким образом, этимологический поиск для рассматриваемого потамонима сводится к этимологизации основы мерга. Зачастую неясные основы в топонимии восходят к сильно изменённым, либо вышедшим из употребления антропонимам - не исключено, что здесь мы имеем дело с подобным случаем. Также возможно, что данная основа восходит к эрзя-мордовскому зоониму нерьгаз - 'барсук': переход инициального [н] в [м] в мордовской топонимии описан Д.В. Цыганкиным, на примере гидронима Мерлей, в основе которого лежит эрзя-мордовское нерь - 'мыс' [5]. Сравните также диалектную вариацию зоонима нетьказ/метьказ - 'ящерица' в эрзя-мордовских говорах Самарского Поволжья (в эрзянском говоре Мордово-Аделяково данный зооним имеет форму метьказ (ПМА, Самарская область, Исаклинский район, Мордово-Аделяково, 2019)). Нам, однако, представляется более верным этимологическое решение для данной основы от глагола мерьгомс (мокша-мордовское мярьгомс; эрзя-мордовское меремс, диалектное - мерьгомс) - 'говорить'. В этом случае потамоним может рассматриваться в одном семантическом ряду с такими названиями как Журчащий ручей, Говорливый ручей и т.д., встречающимися в русской топонимии применительно к ручьям с шумным течением.

Пекшелей Овраг между сёлами Мордово-Аделяково и Захаркино. Название является двусоставным, на русский язык с эрзя-мордовского переводится следующим образом: пекше - 'липа' + лей - 'река; овраг' = 'липовый овраг'. Надо отметить, что значение 'овраг; долина' для лексемы лей является архаичным и, возможно, первич- 
ным, поскольку только такое значение приводится для данной лексемы в наиболее раннем дошедшем до нас лексикографическом памятнике мордовских языков [7]. В современных захаркинском и мордовоаделяковском говорах эрзя-мордовского языка лексема лей употребляется только в значениях 'река' и 'ручей', овраги обозначаются термином латко (ПМА, Самарская область, Сергиевский район, Захаркино, 2019; ПМА, Самарская область, Исаклинский район, Мордово-Аделяково, 2019). Неясно, является ли формант лей в данном топониме подтверждением того, что ранее рассматриваемая лексема бытовала в данных говорах и в значении 'овраг', или же на изменение семантики топонима повлияли какие-то экстралингвистические факторы (например: пересыхание ручья в овраге).

Пойколка Роща в окрестностях села Мордово-Аделяково. Топоним является двусоставым, на русский язык с эрзя-мордовского переводится следующим образом: пой - 'осина' + колка - фонетически адаптированный в эрзя-мордовской этноязыковой среде русский термин колок = 'осиновая роща'.

Пойколкань Родник в осиновой роще, носящей название Пойколка. К данному названию при наименовании родника добавляется мордовский аффикс принадлежности нь, после чего: Пойколка + нь = Пойколкань - 'Осиноворощинский'.

Покш моховой Ручей в окрестностях сёл МордовоАделяково и Мордово-Ишуткино. Потамоним составляет дуальную систему с потамонимом Вишке моховой. Название является гибридным: эрзя-мордовское покш - 'большой' + русское моховой = 'большой моховой (ручей)'.

Попань лисьма Родник в окрестностях села Мордово-Ишуткино, используется для водоснабжения села. На русский язык с эрзя-мордовского название переводится следующим образом: non - заимствование из русского языка - 'священнослужитель' + нь - мордовский аффикс общности + лисьма - 'родник' = 'Поповский родник'. Составляющая nonaнb/nonoнb/non присутствует в эрзянских говорах Самарского Поволжья применительно к названиям всех объектов, которые так или иначе связаны с церковью.

Сэдь бе Название части села Мордово-Аделяково. Со слов информаторов: «Это место такое у нас. Сэдь бе - это значит: около моста» (ПМА, Самаркая область, Исаклинский район, Мордово-Аделяково, 2019). Топоним является двусоставным, переводится с эрзя-мордовского языка на русский следующим образом: сэдь - 'мост' + бe (озвончённая форма термина пе) - 'конец; улица; район села' = 'район села у моста'.

Стаханов Название части села Мордово-Аделяково, строившейся в советское время. Со слов информаторов: «Модное название в советское время было, движение такое было, вот потому и назвали» (ПМА, Самарская область, Исаклинский район, Мордово-Аделяково, 2019).

торговой лисьма Родник в селе Мордово-Ишуткино, на берегу реки Ишуткина лей. Топоним является гибридным: торговой - фонетическая адаптация в эрзя-мордовской этноязыковой среде русской лексемы торговый + лисьма - 'родник' = 'торговый родник'. Мотивацию названия выяснить не удалось: возможно, в этом месте раньше проводилась ярмарка или располагалась торговая лавка.

Трокс куринка Название одной из улиц в селе Мордово-Аделяково, в настоящее время официальное название данной улицы - 'улица Ленина'. Топоним является двусоставным: трокс - 'через; поперёк' + куринка - 'улица' = 'поперечная улица'. Элементы подобного рода часто фиксируются в топонимических пространствах эрзямордовских сёл, в зависимости от их расположения [2]. По частоте встречаемости, данный элемент находится в них на третьем месте, после рассмотренных выше Ало пе и Bepe ne.

удалсь улься Одна из улиц в селе Мордово-Аделяково. Со слов информаторов: «Самая дальняя она от въезда была, улица эта. Задки, то есть. Поэтому и называется задней» (ПМА, Самарская область, Исаклинский район, Мордово-Аделяково, 2019). Топоним является двусоставным: удалие - 'задний' + ульця - фонетически адаптированное в эрзя-мордовской этноязыковой среде заимствование из русского языка улица = 'задняя улица'. В соответствии с фонетическими особенностями мордовоаделяковского говора эрзя-мордовского языка, звук [ц] перешёл в [c]: удалсь улься.

Шикуновский родник Название родника, расположенного в окрестностях урочища Мазы луга - 'Красивый луг.' Название русское, восходит к антропониму - фамилии Шикунов.

щепкань каямо латко Урочище между сёлами Захаркино и Мордово-Аделяково. Место в овраге Пекшелей, куда выбрасывали мешок с щепками, остававшимися после выделки гроба и креста. Буквальный перевод топонима с эрзя-мордовского языка на русский следующее: щепка - заимствование из русского языка + нь мордовский аффикс принадлежности + каямо - 'выброс; отброс' + латко - 'овраг' = 'овраг щепкового выброса'. Топонимы подобного рода с той же мотивировкой - не редкость в топонимических пространствах мордовских сёл, ряд примеров приводит Д.В. Цыганкин [5].

Подводя итог проведённому исследованию, надо отметить, что топонимическое пространство села Мор- 
дово-Аделяково, в целом, обладает основными характеристическими чертами эрзянских топонимических пространств.

Здесь нашли своё отражение основные элементы эрзянской топонимической номенклатуры, ярче всего проявляющиеся в урбонимии, прослеживается эрзя-мордовская структура построения географических названий, выделяется активное использование в топогенезе эрзянской и заимствованной из русского языка географической лексики.

Из отличительных особенностей исследуемого топонимического пространства можно выделить следующие: в топогенезе мордовоаделяковского говора значительное место занимают оригинальные и адаптированные русские лексемы; топонимическая номенклатура отражает характерные особенности данного говора - в частности, замену [ц] на [c] и нерегулярную редукцию финального гласного, акцентологию; в исследуемом топонимическом пространстве имеется несколько ключевых элементов, вокруг которых выстраивается топонимическая система - как лексически, так и семантически, например - Мазы луга.

\section{Принятые сокрашения}

ПМА - Полевые материалы автора.

\section{ЛИТЕРАТУРА}

1. Беленов Н.В. Географические термины для обозначения озёр в мокша-мордовских говорах Самарской Луки//Финно-угорский мир. 2020. Т. 12. №2. СС. $122-129$.

2. Беленов Н.В. Топонимическое пространство эрзя-мордовского села Большая Ёга Самарской области//Вестник угроведения. 2020. Т. 10. №3. СС. 407 - 416.

3. РГАДА. Ф 350 Ревизские сказки и ландратские книги оп. 2 Д. 3351 П.591-606.

4. Симаков В.Е. Энциклопедия чувашских сёл Самарской области. - Самара, 2008.

5. Ц Цыганкин Д.В. Память, запечатлённая в слове: словарь географических названий Республики Мордовия. - Саранск, 2005.

6. Paasonen H. Mordwinische Worterbuch. Helsinki: Societe Finno-Ougrienne, 1990 - 1996.

7. Witsen N. Noord en oost Tartarie. Deel 2. Amsterdam, 1692.

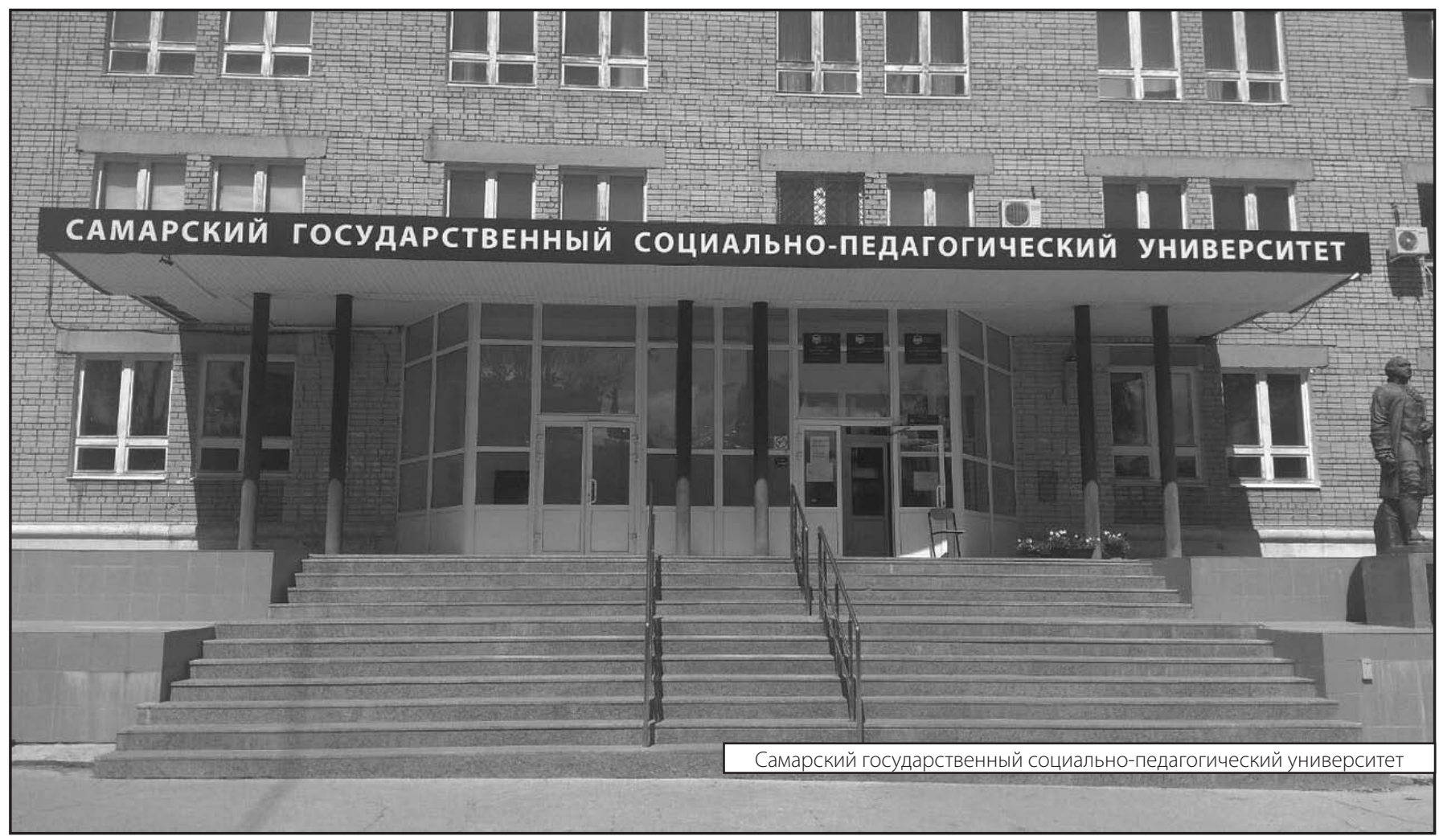

